\title{
Evaluation of podiatric disorders in a sample of children with intellectual disabilities: an analytical cross-sectional study
}

\author{
Laura Cala-Pérez', Marta Elena Losa-Iglesias", David Rodríguez-Sanz"II, vi , César Calvo-Lobo"v , Daniel López-López" \\ Ricardo Becerro-de-Bengoa-Vallejo ${ }^{\text {vI }}$
}

Cala Clinic of Podiatry and Surgery, Asturias, Spain

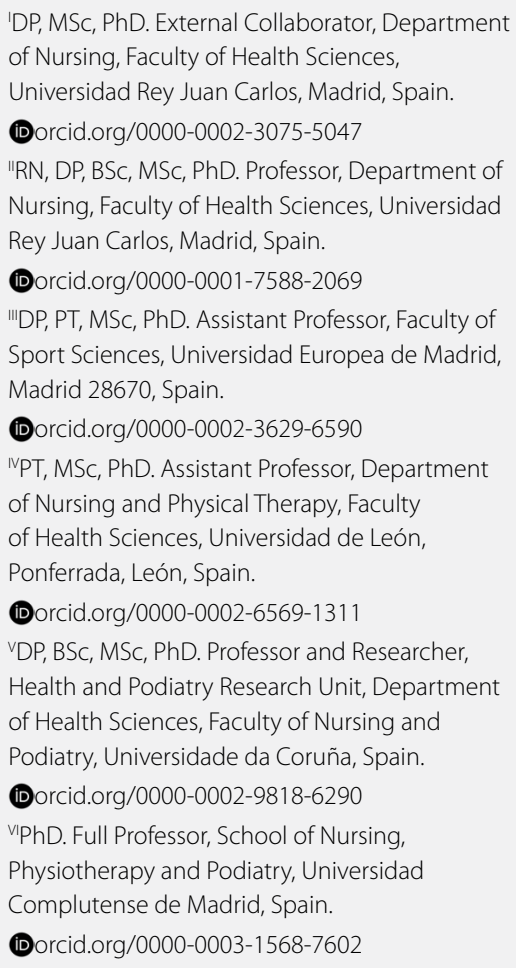

KEY WORDS:

Disabled children.

Foot.

Foot injuries.

Intellectual disability.

Musculoskeletal disease.

\begin{abstract}
BACKGROUND: Intellectual disabilities (IDs) usually derive from neurodevelopmental disabilities. They limit intellectual functioning and cause adaptive behaviors and orthopedic problems. These disabilities have harmful effects on health, everyday practical skills and social functioning, and they diminish quality of life. The goal of our research was to perform podiatric evaluations on schoolchildren with and without ID and ascertain their records of foot disorders.

DESIGN AND SETTING: Analytical cross-sectional study conducted at a podiatric clinic in the city of Piedras Blancas, province of Asturias, Spain.

METHODS: An analytical cross-sectional study on 82 schoolchildren affected by ID, compared with 117 healthy schoolchildren, was conducted at a podiatric clinic. Demographic data, clinical characteristics and measurements relating to podiatric examinations were recorded among the participants who completed all phases of the tool that was used in the study process.

RESULTS: Almost $90 \%$ of the schoolchildren with and without ID presented foot disorders relating to smaller toes, nail disorders, flat feet or lower-limb alterations.

CONCLUSIONS: The participants showed elevated prevalence of foot disorders. Podiatric evaluations are a significant means for preventing the appearance of medical conditions and/or foot problems, and they also improve general health.
\end{abstract}

\section{INTRODUCTION}

Intellectual disabilities (IDs) are a grouping of developmental diseases characterized by impairment of cognitive functions. They give rise to learning difficulties, adaptive behavior and diminished abilities. ${ }^{1}$ The prevalence of ID is around $1-2 \%$ in countries of various income levels. ${ }^{2,3}$ Presence of IDs has been correlated with a myriad of conditions, including genetic syndromes, ${ }^{4}$ genitourinary system diseases, physical health problems, ${ }^{5}$ psychiatric alterations,${ }^{6}$ seizure disorders $^{7}$ and foot problems, ${ }^{8}$ among others. ${ }^{9}$

Currently, over $72 \%$ of people with IDs present foot disorders. However, management of these individuals' foot health is often ignored, underestimated or neglected. These individuals tend not to have good access to foot care through regular podiatric examinations. ${ }^{10}$ Moreover, foot conditions may have a negative impact on overall health. These individuals may present higher incidence of orthopedic foot surgery, relating to pathological conditions of greater severity. ${ }^{11,12}$

Furthermore, foot disorders are associated with fatigue, difficulties in walking, ${ }^{13}$ postural problems ${ }^{14}$ and foot pain. These conditions affect people both with and without ID regarding their activities of daily life. ${ }^{15}$ The value of taking IDs into account is recognized by clinicians and healthcare policymakers, ${ }^{6}$ given the high incidence of foot disorders. ${ }^{8}$ Nonetheless, the prevalence of foot alterations and disorders in the ID population is unknown because of the scarcity of epidemiological studies. Hence, early diagnosis and control over foot disorders, general disorders and musculoskeletal conditions, and avoidance of use of inappropriate shoes, have important benefits for overall health, social functioning and mobility among people with IDs. ${ }^{8}$

\section{OBJECTIVE}

The goal of our study was to perform podiatric evaluations on schoolchildren with and without ID and to compare their records of foot disorders. We hypothesized that schoolchildren both 
with and without ID would show presence of increased prevalence of foot conditions, in this period of life of the school-age population.

\section{METHODS}

\section{Participants}

This was an analytical cross-sectional study conducted at a podiatric clinic in the city of Piedras Blancas, province of Asturias, Spain, between January 2013 and January 2015. A non-randomized and consecutive sampling method was used to select schoolchildren who were affected by ID, according to the Diagnostic and Statistical Manual of Mental Disorders (DSM-5), ${ }^{16}$ in comparison with healthy schoolchildren. The sample size calculation is described below.

Three follow-up visits were made during the period of this study: after one year (first follow-up visit in 2013), after two years (second follow-up visit in 2014) and after three years (third follow-up visit in 2015). The parents and/or legal guardians of these children provided informed consent for them to take part in the study.

The inclusion criteria for cases in this study were that they needed to present deficits in intellectual functioning and adaptive functioning that were registered in their historical medical records, in accordance with the criteria of the Diagnostic and Statistical Manual of Mental Disorders, ${ }^{17}$ but without any clinical signs of dementia, or any previous surgery or other significant orthopedic treatments. The subjects that participated as controls had no register of ID or medical problems in their medical records.

The exclusion criteria included the following situations: previous history of cardiovascular disease, being immunocompromised, having suffered foot trauma or undergone previous foot surgery, having major orthopedic malformations, presence of a neurological condition, being non-autonomous or semi-autonomous in daily activities, refusal of parents to sign the informed consent form and incapacity to comprehend the instructions relating to the investigation and/or carry them out. Controls were matched to cases, in conformity with their ages.

\section{Procedure}

At enrolment, anthropometric measurements were made, data were collected and a detailed podiatric examination was performed, always by the same trained podiatric evaluator. The first step, before any measurements were made, was to record information regarding the subjects' general health status, demographic characteristics, gender, age and history of injuries, at their visit to the podiatric clinic. This was done for all participants, with or without ID. After participants had been found to be eligible for inclusion in the study, their anthropometric data were collected. The body mass index (BMI) was calculated from the subjects' weight in kilograms, divided by the square of their height in meters, i.e. BMI $=$ weight $/$ height ${ }^{2}\left(\mathrm{~kg} / \mathrm{m}^{2}\right){ }^{18}$

The participants were then divided into two groups of schoolchildren: with and without ID, matched according to age. They took off their shoes and socks for podiatric examinations to be conducted. These examinations followed the protocol described by Concolino et al., ${ }^{19}$ using a Waldrop scale,${ }^{20}$ in which a single researcher assessed the legs using a LED podoscope device (Herbitas.com, Polígono Industrial, Foios, Valencia, Spain). For this appraisal, each child stood barefoot in a bipodal relaxed posture, with feet slightly apart and weight evenly distributed. Static and dynamic examinations were performed to enable detection of biomechanical abnormalities over various periods of time in the gait cycle. This evaluator could not be blind to the subject's ID.

Joint hyperlaxity was then evaluated. The range of foot movement was assessed in terms of abduction, adduction, dorsiflexion, plantar flexion, muscle tone (analyzed through testing manual counter-resistance), integrity of the ankle (evaluated through a drawer test) and patellar subluxation. Moreover, the foot examination involved recognition of the general appearance of the feet, abnormalities of the toes, condition of the toenails, rotation of the feet, presence of arches, foot type and skin pathology. ${ }^{19}$

\section{Sample size calculation}

The sample frame was analyzed using the clinical epidemiology research software of the University of Coruna (http://www.fisterra.com/mbe/investiga/9muestras/9muestras2.asp). The statistical treatment was based on schoolchildren living in the city of Piedras Blancas, in the province of Asturias, northwestern Spain, where the total number of schoolchildren on January 1, 2013, was 123,833 (http://www.ine.es/jaxiT3/Datos.htm?t=9681).

The sample size calculation assumed the following: a two-tailed test, an alpha level of 0.05 , a desired power analysis level of $90 \%$ with a beta level of $5 \%$, a precision of $3 \%$ for a proportion of $50 \%$ $(\mathrm{P}=0.5)$ and a loss of schoolchildren of $15 \%$. From this, it was determined that at least 156 subjects would need to be analyzed.

\section{Ethics considerations}

This study protocol was reviewed and approved by the local research ethics committee (Universidad Rey Juan Carlos, Spain), under registration number 050520165316, with the application date of June 24, 2016. All the parents and/or legal guardians of the participating children signed a written informed consent statement before these participants with or without ID were brought into the study.

\section{Statistical analysis}

Demographic and clinical characteristics were analyzed, including the participants' heights, weights, ages and BMI. The quantitative 
variables were summarized as means and standard deviations (SD), and maximum and minimum values, and comparisons were made between the two groups (with or without ID). Categorical variables were shown as total values and percentages.

All the variables were examined for normality of distribution using the Kolmogorov-Smirnov test. Independent Student $t$ tests were used to find out whether differences were statistically significant when normal distribution was shown. Measurements that were not normally distributed were tested using the nonparametric Mann-Whitney U test. Fisher's exact test was used to compare categorical qualitative variables.

In all of the analyses, the statistical significance level was established as $\mathrm{P}<0.05$. All the analyses were performed using a statistical software package (SPSS 19.0, Chicago, IL, USA).

\section{RESULTS}

\section{Sample characteristics}

A total of 197 children could be included in this study: 80 with ID who were capable of understanding the instructions necessary to carry out the present study; and 117 in the control group. All 197 individuals completed all the stages of the study process: 107 were male $(54.31 \%)$ and 90 were female $(45.68 \%)$. Their ages ranged from 4 to 15 years and their mean age was $8.76 \pm 2.33$ years.

Table 1 shows the descriptive statistics on successive evaluations of age and anthropometric data. Only the variables of weight, height and BMI had normal distribution. The age of the group of participants with disabilities was significantly greater than that of the control group at the beginning of the study, as indicated by the corresponding Student t test for two independent samples. For this reason, the initial weight of the group with disability was significantly greater than that of the control group. In addition, the initial height of the group with disability was greater and the $\mathrm{BMI}$ of the group of children with disabilities was also greater than that of the control group.

Overall, $89.84 \%$ of the participants $(n=177)$ stated that they had suffered from foot problems. Subsequent physical examination revealed that all of them presented non-neutral calcaneal stance, 69 (38.98\%) had hallux deformities, 85 (48.02\%) had metatarsus adductus and 52 (28.37\%) had lower limb pain.

The frequencies of foot and leg pathological conditions, comprising hallux deformities, wide spacing between the $1^{\text {st }}$ and $2^{\text {nd }}$ toes, abnormalities of the $3^{\text {rd }}, 4^{\text {th }}$ and $5^{\text {th }}$ toes, flat foot and lower-limb pain, were greater in the group with intellectual disabilities than in the control group, as shown in Table 2.

The data relating to the range of motion of the foot are shown in Table 3. The dorsiflexion values for the ankle with knee flexed or extended, inversion, eversion and dorsiflexion of the first metatarsophalangeal joint were similar between the two groups. The plantarflexion values for the ankle were higher in the control group, but the group with intellectual disability had a greater range of plantar flexion of the $1^{\text {st }}$ metatarsophalangeal joint.

No significant differences were observed between the two groups regarding the degree of relaxed calcaneal stance or discrepancy between the lower limbs. However, the Chippaux-Smirak index values were found to be greater in the group with intellectual disabilities than in the control group, and ankle plantarflexion was less in the group with intellectual disabilities than in the control group.

\section{DISCUSSION}

We conducted a cross-sectional study consisting of podiatric evaluations on schoolchildren with and without ID and ascertained their records of foot disorders. Today, in Spain, schoolchildren generally do not have good access to foot care through regular podiatric examinations, even in situations in which foot alterations and disorders are present. These are often ignored because of the existence of other major complicating diseases.

Most previous studies on this issue have addressed detection of foot problems in children with ID. ${ }^{19,21,22}$ However, to our knowledge, there are no studies demonstrating that careful podiatric examination among schoolchildren with and without ID shows higher incidence of foot disorders during this period of life of the school-age population.

Table 1. Sociodemographic and clinical characteristics of the sample population

\begin{tabular}{|c|c|c|c|c|}
\hline Variable & $\begin{array}{c}\text { Total group } \\
\text { Mean } \pm \text { SD (range) } \\
\mathrm{N}=197\end{array}$ & $\begin{array}{c}\text { ID group } \\
\text { Mean } \pm \text { SD (range) } \\
N=80\end{array}$ & $\begin{array}{c}\text { Control group } \\
\text { Mean } \pm \text { SD (range) } \\
\mathrm{N}=117\end{array}$ & P-value \\
\hline Age (years) & $8.76 \pm 2.33(4.0-15.0)$ & $9.1 \pm 3.08(4.0-15.0)$ & $8.52 \pm 1.61(6.0-11.0)$ & $0.092^{* *}$ \\
\hline Weight (kg) & $35.04 \pm 13.62(16.60-85.30)$ & $39.39 \pm 17.58(16.6-85.3)$ & $32.1 \pm 9.0(17.7-56.4)$ & $<0.001^{*}$ \\
\hline Height (cm) & $134.73 \pm 13.61(108.70-180.10)$ & $136.90 \pm 17.30(108.2-180.1)$ & $133.25 \pm 10.17(112.0-155.0)$ & $0.064^{*}$ \\
\hline $\mathrm{BMI}\left(\mathrm{kg} / \mathrm{m}^{2}\right)$ & $18.64 \pm 3.99(11.16-32.50)$ & $19.93 \pm 4.82(11.16-32.50)$ & $17.76 \pm 3.03(12.16-26.12)$ & $<0.001^{*}$ \\
\hline
\end{tabular}


Table 2. Frequency of foot and leg pathological conditions in the sample population

\begin{tabular}{|c|c|c|c|c|}
\hline & $\begin{array}{l}\text { Total group } \\
\begin{array}{c}\mathrm{N}=197 \\
\mathrm{n}(\%)\end{array}\end{array}$ & $\begin{array}{l}\text { ID group } \\
\begin{array}{c}\mathrm{N}=80 \\
\mathrm{n}(\%)\end{array}\end{array}$ & $\begin{array}{l}\text { Control group } \\
\qquad \begin{array}{c}\mathrm{N}=117 \\
\mathrm{n}(\%)\end{array}\end{array}$ & P-value \\
\hline Relaxed calcaneal stance (left foot not neutral) & $177(89.84 \%)$ & $70(87.6 \%)$ & $107(91.45 \%)$ & 0.472 \\
\hline Relaxed calcaneal stance position (right foot not neutral) & 169 (85.78\%) & $67(83.75 \%)$ & $102(87.5 \%)$ & 0.537 \\
\hline Hallux deformities & $69(34.67 \%)$ & $38(46.3 \%)$ & $31(26.5 \%)$ & 0.006 \\
\hline Wide space between $1^{\text {st }}$ and $2^{\text {nd }}$ toes & $52(26.39 \%)$ & $14(17.5 \%)$ & $38(35.8 \%)$ & 0.021 \\
\hline Abnormalities of $2^{\text {nd }}$ toe (left foot) & $20(10.15 \%)$ & $9(11.25 \%)$ & $11(9.4 \%)$ & 0.810 \\
\hline Abnormalities of $2^{\text {nd }}$ toe (right foot) & $21(11.65 \%)$ & $12(15.0 \%)$ & $9(7.8 \%)$ & 0.156 \\
\hline Abnormalities of $3^{\text {rd }}$ toe (left foot) & $30(15.07 \%)$ & $20(24.4 \%)$ & $10(8.5 \%)$ & 0.002 \\
\hline Abnormalities of $3^{\text {rd }}$ toe (right foot) & $33(16.58 \%)$ & $21(25.6 \%)$ & $12(10.3 \%)$ & 0.005 \\
\hline Abnormalities of $4^{\text {th }}$ toe (left foot) & $45(22.84 \%)$ & $24(30.0 \%)$ & $21(17.9 \%)$ & 0.057 \\
\hline $2^{\text {nd }}$ toe longer than $1^{\text {st }}$ toe & $42(21.31 \%)$ & $14(17.5 \%)$ & $28(23.9 \%)$ & 0.294 \\
\hline Metatarsus adductus (left foot) & $83(42.13 \%)$ & 27 (33.75\%) & 55 (47.0\%) & 0.077 \\
\hline Metatarsus adductus (right foot) & $84(42.63 \%)$ & $33(41.25 \%)$ & $51(43.6 \%)$ & 0.770 \\
\hline Flatfoot (left foot) & $22(11.05 \%)$ & $19(23.5 \%)$ & $3(2.6 \%)$ & 0.001 \\
\hline Flatfoot (right foot) & 17 (8.54\%) & $14(17.3 \%)$ & $3(2.6 \%)$ & 0.001 \\
\hline Negative foot progression angle & $25(12.56 \%)$ & $9(11.3 \%)$ & $16(13.7 \%)$ & 0.668 \\
\hline Lower limb pain & $52(26.13 \%)$ & $12(26.7 \%)$ & $40(30.2 \%)$ & 0.003 \\
\hline
\end{tabular}

Fisher's exact test was performed. In all the analyses, $\mathrm{P}<0.05$ was considered statistically significant with a $95 \%$ confidence interval.

Table 3. Range of motion of foot and leg: joint pathological conditions in the sample population

\begin{tabular}{|c|c|c|c|c|}
\hline & $\begin{array}{c}\text { Total group } \\
\text { Mean } \pm \text { SD (range) } \\
\mathrm{N}=197\end{array}$ & $\begin{array}{c}\text { ID group } \\
\text { Mean } \pm \text { SD (range) } \\
\mathrm{N}=80\end{array}$ & $\begin{array}{c}\text { Control group } \\
\begin{array}{c}\text { Mean } \pm S D \text { (range) } \\
N=117\end{array}\end{array}$ & P-value \\
\hline Left ankle dorsiflexion (knee extended) & $14.32 \pm 4.48(0.0-28.0)$ & $14.5 \pm 5.3(0.0-27.0)$ & $14.2 \pm 3.8(3.0-28.0)$ & 0.246 \\
\hline Right ankle dorsiflexion (knee extended) & $14.33 \pm 4.54(0.0-30.0)$ & $14.5 \pm 5.4(0.0-30.0)$ & $14.2 \pm 3.9(2.0-26.0)$ & 0.237 \\
\hline Left ankle dorsiflexion (knee flexed) & $19.26 \pm 4.53(0.0-33.0)$ & $19.4 \pm 5.5(0.0-32.0)$ & $19.1 \pm 3.7(7.0-33.0)$ & 0.485 \\
\hline Right ankle dorsiflexion (knee flexed) & $19.35 \pm 4.51(0.0-35.0)$ & $19.7 \pm 5.5(0.0-35.0)$ & $19.1 \pm 3.7(5.0-31.0)$ & 0.114 \\
\hline Right ankle plantarflexion & $16.27 \pm 2.98(4.0-27.0)$ & $53.4 \pm 9.9(5.0-27.0)$ & $56.2 \pm 6.1(4.0-24.0)$ & 0.027 \\
\hline Eversion (left foot) & $17.03 \pm 3.28(0.0-30.0)$ & $17.2 \pm 4.2(0.0-30.0)$ & $16.9 \pm 2.5(5.0-24.0)$ & 0.886 \\
\hline Eversion (right foot) & $16.84 \pm 3.11(0.0-28.0)$ & $17.0 \pm 3.7(0.0-28.0)$ & $16.7 \pm 2.6(4.0-25.0)$ & 0.664 \\
\hline Inversion (left foot) & $37.46 \pm 3.69(5.0-51.0)$ & $37.3 \pm 5.0(5.0-47.0)$ & $37.6 \pm 2.5(30.0-51.0)$ & 0.818 \\
\hline Inversion (right foot) & $37.51 \pm 3.15(20.0-50.0)$ & $37.5 \pm 4.0(20.0-49.0)$ & $37.6 \pm 2.5(33.0-50.0)$ & 0.606 \\
\hline Dorsiflexion of $1^{\text {st }}$ metatarsophalangeal joint (right foot) & $77.59 \pm 10.14(15.0-93.0)$ & $77.2 \pm 11.7(15.0-93.0)$ & $77.8 \pm 9.0(44.0-93.0)$ & 0.506 \\
\hline Relaxed calcaneal stance position (grades) (left foot) & $4.74 \pm 3.26(-5.0-13.0)$ & $4.7 \pm 3.7(-5.0-13.0)$ & $4.8 \pm 2.9(-2.0-12.0)$ & 0.932 \\
\hline Relaxed calcaneal stance position (grades) (right foot) & $3.85 \pm 3.11(-5.0-12.0)$ & $4.2 \pm 3.6(-3.0-12.0)$ & $3.6 \pm 2.8(-5.0-12.0)$ & 0.616 \\
\hline Chippaux-Smirak index (left foot) & $34.53 \pm 17.66(0.0-84.0)$ & $40.7 \pm 19.1(0.0-84.0)$ & $30.2 \pm 15.3(0.0-73.0)$ & $<0.001$ \\
\hline Chippaux-Smirak index (right foot) & $37.28 \pm 18.55(0.0-90.0)$ & $43.3 \pm 19.4(7.0-90.0)$ & $33.1 \pm 16.8(0.0-81.0)$ & $<0.001$ \\
\hline Lower limb length discrepancy (mm) & $8.4 \pm 6.50(3.0-30.0)$ & $14.0 \pm 9.5(5.0-30.0)$ & $6.0 \pm 2.5(3.0-10.0)$ & 0.062 \\
\hline
\end{tabular}

ID = intellectual disabilities; SD = standard deviation. In all the analyses, $\mathrm{P}<0.05$ (with a 95\% confidence interval) was considered statistically significant. P-values are from Mann-Whitney $U$ test. 
Our research demonstrated that careful podiatric examination during the school-age period showed elevated incidence of foot conditions. Most of the anomalies that we found may have been secondary to hypotonia and laxity of the muscles and ligaments. ${ }^{19,23}$ This was similar to the findings from other studies that have investigated foot problems, and it suggests that the most critical problems are based on other, less common orthopedic abnormalities. ${ }^{24,25}$

There are important variations relating to the morphology and function of the lower extremities during the school-age period. These contribute towards changes relating to postural sway, variations in plantar loading patterns during gait and presence of flatter feet or greater pronation in the foot, with higher prevalence of bunions, pain, muscle weakness and smaller-toe alterations, increased plantar pressure and difficulty in putting shoes on. ${ }^{26}$

This study had some limitations that need to be acknowledged. Firstly, this investigation was conducted at a podiatric clinic with a relatively small number of subjects. Secondly, a larger and more diverse sample (including children with ID in different countries) would be beneficial, to improve the strength of the study and make it possible to identify more of the mechanisms involved. Thirdly, there was only a single non-blinded evaluator analyzing the participants' feet. Future studies should have at least two blinded evaluators: one evaluator to examine the alterations and deformities of the feet and another to manage the disorders of the lower limbs, in comparison with the blinded data that has been recorded. Despite the existence of obvious demographic differences between the ID and control groups, future studies should consider using normalized demographic data in order to compare the group with ID with a matched paired control group.

The issues highlighted above show that there is a need for further continuous research on this trend, in order to analyze different foot conditions and the therapeutic interventions that physicians could use to improve foot health during the school-age period.

\section{CONCLUSION}

Our study showed that clinical signs such as hallux deformities, abnormalities of the third, fourth and fifth toes, flat feet, limited range of motion for ankle plantarflexion and for first metatarsophalangeal joint and higher Chippaux-Smirak index (i.e. showing flat feet) were clinical characteristics with higher prevalence among children with intellectual disabilities, compared with a control group.

\section{REFERENCES}

1. Salvador-Carulla L, Reed GM, Vaez-Azizi LM, et al. Intellectual developmental disorders: towards a new name, definition and framework for "mental retardation/intellectual disability" in ICD-11. World Psychiatry. 2011;10(3):175-80. PMID: 21991267.
2. Maulik PK, Mascarenhas MN, Mathers CD, Dua T, Saxena S. Prevalence of intellectual disability: a meta-analysis of population-based studies. Res Dev Disabil. 2011;32(2):419-436. PMID: 21236634; doi: 10.1016/j. ridd.2010.12.018.

3. Durkin M. The epidemiology of developmental disabilities in lowincome countries. Ment Retard Dev Disabil Res Rev. 2002;8(3):206-11. PMID: 12216065; doi: 10.1002/mrdd.10039.

4. Xiao B, Qiu W, Ji X, et al. Marked yield of re-evaluating phenotype and exome/target sequencing data in 33 individuals with intellectual disabilities. Am J Med Genet A. 2018;176(1):107-15. PMID: 29159939; doi: 10.1002/ajmg.a.38542.

5. Matson JL, Cervantes PE. Comorbidity among persons with intellectual disabilities. Res Autism Spectr Disord. 2013;7(11):1318-22. doi: 10.1016/J. RASD.2013.07.018.

6. McCarron M, Swinburne J, Burke E, et al. Patterns of multimorbidity in an older population of persons with an intellectual disability: Results from the intellectual disability supplement to the Irish longitudinal study on aging (IDS-TILDA). Res Dev Disabil. 2013;34(1):521-7. PMID: 23085501; doi: 10.1016/J.RIDD.2012.07.029

7. Turygin N, Matson JL, Adams H. Prevalence of co-occurring disorders in a sample of adults with mild and moderate intellectual disabilities who reside in a residential treatment setting. Res Dev Disabil. 2014;35(7):1802-8. PMID: 24656808; doi: 10.1016/j.ridd.2014.01.027.

8. Courtenay K, Murray A. Foot Health and Mobility in People With Intellectual Disabilities. J Policy Pract Intellect Disabil. 2015;12(1):42-6. doi: 10.1111/jppi.12105.

9. Folch-Mas A, Cortés-Ruiz MJ, Vicens-Calderón P, Martínez-Leal R. Health profiles in people with intellectual developmental disorders. Salud Publica Mex. 2017;59(4):400-7. PMID: 29211260; doi: 10.21149/8199.

10. Lennox TN, Nadkarni J, Moffat P, Robertson C. Access to Services and Meeting the Needs of People with Learning Disabilities. J Learn Disabil. 2003;7(1):34-50. doi: 10.1177/1469004703007001604.

11. Michael J. Healthcare for people with disabilities. 2009. Available from: https://www.professionalstandards.org.uk/docs/defaultsource/publications/policy-advice/healthcare-for-people-withdisabilities-2009.pdf?sfvrsn=93c77f20_8. Accessed in 2018 (Nov 1).

12. Bonanno DR, Medica VG, Tan DS, et al. Evaluating the outcomes of a podiatry-led assessment service in a public hospital orthopaedic unit. J Foot Ankle Res. 2014;7(1):45. PMID: 25419238; doi: 10.1186/s13047014-0045-6.

13. Almuhtaseb S, Oppewal A, Hilgenkamp TI. Gait characteristics in individuals with intellectual disabilities: a literature review. Res Dev Disabil. 2014;35(11):2858-83. PMID: 25105568; doi: 10.1016/j. ridd.2014.07.017.

14. Lee K, Lee M, Song C. Balance training improves postural balance, gait, and functional strength in adolescents with intellectual disabilities: Single-blinded, randomized clinical trial. Disabil Health J. 2016;9(3):416-22. PMID: 26975417; doi: 10.1016/j.dhjo.2016.01.010. 
15. Evans A, Menz H, Bourke J, et al. Podiatry. In: Rubin IL, Merrick J, Greydanus DE, Patel DR, editors. Health Care for People with Intellectual and Developmental Disabilities across the Lifespan. Cham: Springer; 2016. p. 1845-65. doi: 10.1007/978-3-319-18096-0_142.

16. First MB. DSM-5 $5^{\oplus}$ Handbook of Differential Diagnosis. American Psychiatric Publishing; 2013. doi: 10.1176/appi.books.9781585629992.

17. American Psychiatric Association. Diagnostic and Statistical Manual of Mental Disorders. American Psychiatric Association; 2013. doi: 10.1176/ appi.books.9780890425596.

18. Garrow JS, Webster J. Quetelet's index (W/H2) as a measure of fatness. Int J Obes. 1985:9(2):147-53. PMID: 4030199.

19. Concolino D, Pasquzzi A, Capalbo G, Sinopoli S, Strisciuglio P. Early detection of podiatric anomalies in children with Down syndrome. Acta Paediatr. 2006;95(1):17-20. PMID: 16373291; doi: 10.1080/08035250500325108.

20. Waldrop MF, Pedersen FA, Bell RQ. Minor physical anomalies and behavior in preschool children. Child Dev. 1968;39(2):391-400. PMID: 4172079.

21. Prasher VP, Robinson L, Krishnan VH, Chung MC. Podiatric disorders among children with Down syndrome and learning disability. Dev Med Child Neurol. 1995;37(2):131-4. PMID: 7851669.

22. Gutiérrez-Vilahú L, Massó-Ortigosa N, Rey-Abella F, Costa-Tutusaus L, Guerra-Balic M. Comparative study of plantar footprints in youth with Down syndrome. Int Med Rev Down Syndr. 2015;19(3):36-42. doi: 10.1016/j.sdeng.2015.05.003.

23. Pau M, Galli M, Crivellini M, Albertini G. Foot-ground interaction during upright standing in children with Down syndrome. Res Dev Disabil. 2012;33(6):1881-7. PMID: 22717405; doi: 10.1016/j.ridd.2012.05.018.

24. Diamond LS, Lynne D, Sigman B. Orthopedic disorders in patients with Down's syndrome. Orthop Clin North Am. 1981;12(1):57-71. PMID: 6451852.

25. Pikora TJ, Bourke J, Bathgate K, et al. Health conditions and their impact among adolescents and young adults with Down syndrome. PLoS One. 2014;9(5):e96868. PMID: 24818963; doi: 10.1371/journal.pone.0096868.

26. Scott G, Menz HB, Newcombe L. Age-related differences in foot structure and function. Gait Posture. 2007;26(1):68-75. PMID: 16945538; doi: 10.1016/j.gaitpost.2006.07.009

Acknowledgements: We would like to thank the patients who were recruited at the podiatric clinic, along with the staff at this clinic, in the city of Piedras Blancas, province of Asturias, Spain

\section{Sources of funding: None}

Conflict of interest: The authors did not receive any financial assistance from or have any personal relationships with other people or organizations that might have inappropriately influenced (biased) their work
Date of first submission: May 8, 2018

Last received: Sept 27, 2018

Accepted: November 16, 2018

\section{Address correspondence:}

Daniel López López

Health and Podiatry Research Unit, Department of Health Sciences, Faculty of Nursing and Podiatry, Universidade da Coruña Campus Universitário de Esteiro s/no

15403 Ferrol — Spain

E-mail: daniellopez@udc.es 